\title{
Gestão do conhecimento tácito no desenvolvimento de produtos estudo de casos em empresas do setor automobilístico
}

\author{
Marcio Shoiti Kuniyoshi Doutor em Administração. Universidade de São Paulo (USP) - Brasil. mskunfea@gmail.com \\ Renata de Almeida Vianna Gava Mestre em Administração. Universidade Metodista de São Paulo - Brasil. \\ renata.gava@metodista.br \\ Marcos Antonio Gaspar Doutor em Administração pela USP. Universidade Nove de Julho (UNINOVE) - Brasil. \\ marcos.antonio@uni9.pro.br \\ Ruggero Ruggieri Mestrando em Informática e Gestão do Conhecimento. Universidade Nove de Julho (UNINOVE) - \\ Brasil. ruggero.ruggieri@hotmail.com
}

\section{RESUMO}

Esta pesquisa tem como objetivo identificar as principais práticas utilizadas para a criação e disseminação do conhecimento tácito no desenvolvimento de produtos em empresas do setor automobilístico. Para tanto, foi desenvolvida uma pesquisa descritiva qualitativa executada por meio de estudos de caso. A pesquisa foi realizada em duas empresas automobilísticas de grande porte atuantes na Região do $A B C$ (SP), nas quais gestores de funcionários da área de desenvolvimento de produtos responderam ao roteiro de entrevista semiestruturada delineado. 0 roteiro de entrevistas foi composto por: a) Perfil da empresa e do respondente, b) Identificação das práticas utilizadas para a criação e disseminação do conhecimento tácito e c) Identificação das contribuições das práticas de criação e disseminação do conhecimento tácito. As principais práticas verificadas nas duas empresas para a criação e disseminação do conhecimento tácito foram bastante similares, possivelmente em razão de ambas atuarem no setor automobilístico, embora a operacionalização destas tenha assumido características distintas em cada uma delas. As práticas de criação e disseminação de conhecimento tácito verificadas foram o incentivo a cursos regulares e de especialização, socialização de indivíduos por meio de reuniões periódicas, grupos de estudo, brainstorming, lições aprendidas, knowledge cafés e conversas informais constantes entre os colaboradores.

Palavras-chave: Conhecimento tácito. Disseminação de conhecimento. Gestão do conhecimento. Conhecimento organizacional.

\section{Tacit knowledge management in product development: case studies on companies in the automotive industry}

\begin{abstract}
This research aims to identify the main practices used for the creation and dissemination of tacit knowledge in product development process in automotive industry companies. This descriptive qualitative research was performed by case study. The survey was conducted in two large automobile companies in the ABC Region (Brazil - State of São Paulo). The staff managers of product development areas responded to semi-structured interviews script that was composed by a) Company and interviewed profile, b) Practices applied for creation and dissemination of tacit knowledge, and c) Identification of the contributions of creation and dissemination of tacit knowledge. The main practices observed in the two companies for the creation and dissemination of tacit knowledge were very similar, possibly due to the fact that both work in the automotive industry, although the operationalization of these practices assumed distinct features in each one of them. The creation and dissemination of tacit knowledge practices verified were the encouragement of regular courses and specialization, socialization of individuals through regular meetings, study groups, brainstorming, lessons learned, knowledge cafes and constant informal conversations among the employees.
\end{abstract}

Keywords: Tacit knowledge. Dissemination of knowledge. Knowledge management. Organizational knowledge. 


\section{INTRODUÇÃO}

O conhecimento tornou-se um importante recurso para as organizações contemporâneas inseridas em um contexto de negócios complexo e mutável. Assim, em organizações focadas no conhecimento, a preocupação com a criação e compartilhamento de conhecimentos é crucial a fim de a organização empreender a gestão estratégica do conhecimento organizacional, reconhecendo-o como fonte essencial de vantagem competitiva (KLEIN, 1998; PORTER, 1998). Isto porque, conforme apregoam Brito, Galvão e Oliveira (2012) e Centenaro, Bonemberger e Laimer (2016), o conhecimento organizacional tornou-se fonte de valor e criador de diferenciais competitivos à medida que proporciona inovação por meio da gestão do capital intelectual, que é incorporado a produtos, serviços e no processo de tomada de decisão pelas pessoas, tecnologias de informações e processos organizacionais.

Desta forma, o conhecimento e, consequentemente, sua gestão são recursos estratégicos de grande valia às organizações modernas (EISENHARDT; SANTOS, 2002). A atual relevância da gestão do conhecimento se dá pela preocupação das organizações em utilizarem de forma estratégica ações concretas relativas à valorização do indivíduo, ou seja, à valorização do capital intelectual existente na organização por meio de seus colaboradores.

Nesse contexto, nas organizações existem distintas maneiras de criar e difundir o conhecimento, aspectos estes presentes em seus ambientes e que devem ser considerados em suas estratégias organizacionais. Para tanto, percebe-se a ênfase dada à análise dos mecanismos de criação e disseminação do conhecimento por meio do conhecimento tácito dos indivíduos, ou seja, àquele que não é visível, difícil de formalizar, mensurar e perceber. Desta forma, ressalta-se a importância da pesquisa sobre a gestão do conhecimento, mais especificamente quanto ao conhecimento tácito.

Kuniyoshi et al. (2013) indicam que a gestão do conhecimento seja uma abordagem relativamente recente da Administração contemporânea, cujo foco engloba o conceito de conhecimento como recurso estratégico, sendo que suas técnicas, práticas e iniciativas gerenciais encontram-se em momento de consolidação. Assim, Carvalho e Hinça (2004) atentam que o desafio das organizações seja converter o conhecimento de seus colaboradores em conhecimento organizacional. Todavia, não há uma receita pronta de como gerir o conhecimento tácito para todas as organizações. Filenga (2014) indica que cada vez mais as empresas de diversos setores de atuação passam a valorizar o conhecimento existente (interno e externo) como um componente estratégico para o seu negócio.

\subsection{Objetivo geral}

O objetivo desta pesquisa é identificar as principais práticas utilizadas para a disseminação do conhecimento tácito no desenvolvimento de produtos em empresas do setor automobilístico.

\section{REFERENCIAL TEÓRICO}

A plataforma teórica elaborada aborda os principais tópicos que compõem a temática proposta nesta pesquisa: a gestão do conhecimento e o conhecimento tácito nas organizações.

\subsection{Gestão do conhecimento nas organizações}

Nonaka e Von Krogh (2009) afirmam que o conhecimento está relacionado às crenças e compromissos do indivíduo, criando assim um significado único para ele. No contexto corporativo, os autores entendem que os conhecimentos da organização devam ser amplamente disseminados entre os seus colaboradores. No entanto, Ferraresi et al. (2012) argumentam que a qualidade do conhecimento na organização é revelada na diversidade de capacitações que a empresa possui como resultado desse conhecimento. Dessa forma, as organizações se esforçam para melhorar a capacidade de inovação e sua competitividade, estando sua 
atenção cada vez mais focada em como gerenciar seus ativos intangíveis, dentre os quais o conhecimento se destaca na atualidade (LÓPEZ-NICOLÁS; MEROÑO-CERDÁN, 2011).

De acordo com Andrade, Ferreira e Pereira (2010), o termo gestão do conhecimento implica na utilização de mecanismos que auxiliem as organizações a gerenciarem o conhecimento como um ativo que promova o desenvolvimento organizacional. Ainda de acordo com os autores, a gestão do conhecimento busca a aproximação entre o homem e as tecnologias da informação, obtendo como resultado, a potencialização da capacidade cognitiva do ser humano no âmbito organizacional.

A gestão do conhecimento no ambiente organizacional demanda a utilização de ferramentas que as organizações possam utilizar em prol da facilitação do atingimento de suas metas e objetivos; tornando-se assim uma ferramenta estratégica. Outrossim, conforme argumentam Kuniyoshi et al. (2013), é necessária a compreensão de como a gestão do conhecimento contribui para a criação e manutenção de competências essenciais, sendo que com a adoção de práticas e iniciativas de gestão do conhecimento, supõe-se a que a compreensão de fatores internos ou externos que podem afetar o poder competitivo das empresas passe a ser melhor compreendido.

Para Teixeira Filho $(2000$, p. 22), a "gestão do conhecimento pode ser vista como uma coleção de processos que governa a criação, disseminação e utilização do conhecimento para atingir plenamente os objetivos da organização". Wong (2013) afirma que a gestão do conhecimento repousa no gerenciamento dos recursos e processos de conhecimento da organização, buscando assim agregar maior valor à empresa por meio da utilização dos conhecimentos que impliquem em criação de vantagem competitiva. Santos e Popadiuk (2010) argumentam que a gestão do conhecimento nas organizações passa pela compreensão das características, recursos e competências internas e intrínsecas de cada firma e, também, pelo entendimento das necessidades individuais e coletivas associadas aos processos de criação e aprendizado.

Davenport e Prusak (1998) classificam o conhecimento como tácito e explícito. Para Fleury (2002), o conhecimento tácito é abstrato, subjetivo e provém da experiência específica ao contexto, sendo mais difícil de ser formalizado ou comunicado. Já o conhecimento explícito pode ser estruturado e verbalizado, sendo facilmente transportado, armazenado e compartilhado, seja por meio de documentos ou de sistemas computacionais.

Silva et al. (2011) indicam em seus estudos que a gestão do conhecimento envolva toda a parte intelectual do ser humano para disponibilizar experiências e compartilhar ideias com outros indivíduos na organização. Os autores ainda indicam que administrar o conhecimento proporciona ao capital intelectual da empresa, a geração de novos conhecimentos por meio da aprendizagem e troca de conhecimentos entre todos, bem como facilita a integração entre as pessoas e favorece a cultura organizacional.

Amorin e Tomaél (2011) afirmam que o conhecimento dentro da organização é construído por meio da coletividade, ou seja, as pessoas compartilham informações e experiências que são transformadas em conhecimento, concebendo desta forma, o aprendizado e o desenvolvimento organizacional. Assim, a ação conjunta entre pares e líderes auxilia no processo da disseminação de ações e procedimentos na organização, partindo das informações para o conhecimento.

\subsection{Conhecimento tácito nas organizações}

Embora o conhecimento tácito tenha sido mencionado nas seções anteriores, sua importância para as organizações atuais remete à necessidade de maior aprofundamento acerca de sua compreensão e caracterização. Assim, o conhecimento tácito trata-se de uma forma de conhecimento difícil de ser comunicada, pois lida essencialmente com o conhecimento pessoal incorporado à experiência profissional do indivíduo. Carbone et al. (2009) afirmam que o conhecimento tácito acumulado pelos indivíduos precisa ser disseminado aos demais membros da organização.

Silva et al. (2011) indicam que a explicitação do conhecimento tácito é defendida por diversos autores. Porém, a tarefa de torná-lo explícito é complexa, pois requer observação e estímulo ao diálogo e integração dos indivíduos na organização. Ainda de acordo com os autores, um dos principais desafios da gestão do 
conhecimento é garantir ao indivíduo que compartilhar seu conhecimento seja mais lucrativo do que retê-lo somente para si.

Carvalho e Hinça (2004) propõem que o conhecimento tácito não deve ser buscado somente no âmbito do indivíduo. A organização tem suas rotinas específicas, normas de conduta e códigos de informação, podendo ser considerada como uma unidade que detém conhecimentos, em grande parte de natureza tácita. Entretanto, Leite, Gontijo e Meneghelli (2010) argumentam que o conhecimento tácito se torna importante por representar a experiência acumulada do indivíduo, o que pode contribuir para a competitividade da empresa.

Nonaka e Takeuchi (1997) indicam que a organização deva mobilizar o conhecimento tácito, criado e acumulado ao nível individual, de forma que a conversão do conhecimento ocorra continuamente, ampliando em escala cada vez maior e, assim, cristalizando-se em níveis ontológicos superiores na coletividade da organização. A Figura 1 apresenta as diferentes formas de conversão do conhecimento, de acordo com 0 modelo proposto pelos autores. A espiral do conhecimento ao centro da figura indica a dinâmica de interação de forma a representar o conteú do relativo aos conhecimentos (tácitos e explícitos) gerados nos quatro modos de conversão do modelo e que interagem entre si de forma dinâmica.

A espiral do conhecimento se manifesta quando ocorre o intercâmbio entre o conhecimento tácito e o conhecimento explícito na organização. Desta forma, o indivíduo transforma o seu conhecimento em algo que pode ser repassado aos demais colaboradores (NONAKA; TAKEUCHI, 1997).

Figura 1 - Conversão de conhecimentos na organização

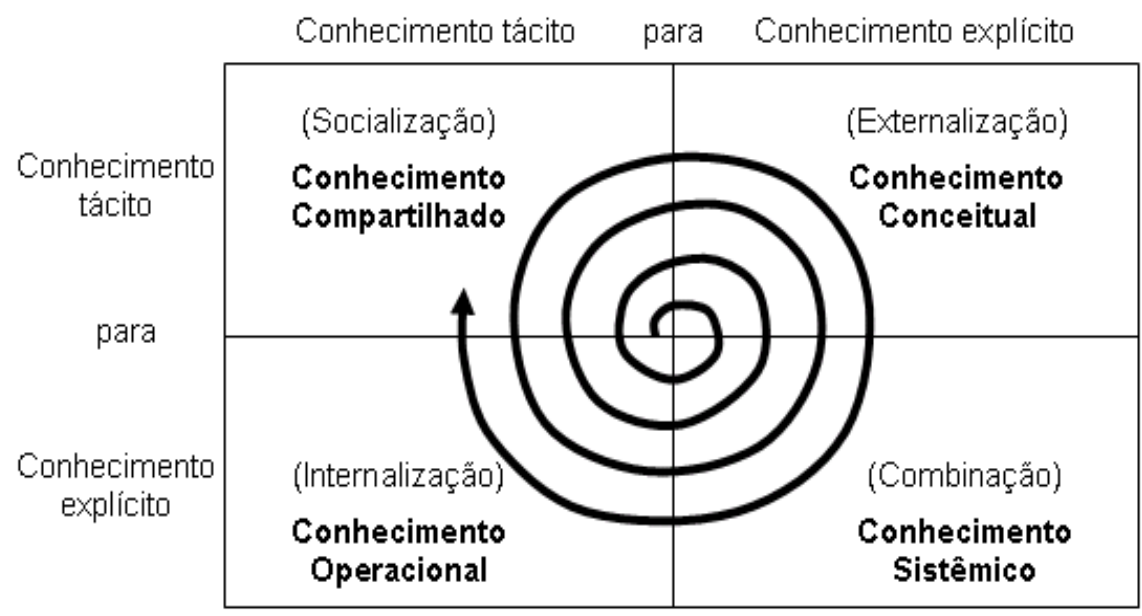

Fonte: Nonaka e Takeuchi (1997, p. 80).

Nonaka e Takeuchi (1997) indicam que a conversão de conhecimento tácito em novo conhecimento tácito seja denominada socialização. A conversão de conhecimento tácito em conhecimento explícito é denominada externalização. Na sequência, a combinação expõe a conversão do conhecimento explícito em novo conhecimento explícito. Por fim, a fase de internalização evidencia a conversão do conhecimento explícito em novo conhecimento tácito a ser assimilado pelo indivíduo. Segundo os autores, este ciclo de conversão de conhecimentos volta a ocorrer indefinidamente na organização.

Entretanto, Leite, Gontijo e Meneghelli (2010) indicam certas dificuldades para tanto, uma vez que o conhecimento tácito pode se apresentar sob duas dimensões: a primeira de natureza técnica, que pode ser compreendida como know-how (saber como fazer) do indivíduo, mas com difícil articulação de seus princípios técnicos; e a segunda de natureza cognitiva, caracterizada por modelos mentais, crenças e percepções do mundo à volta do indivíduo. Almeida, Freitas e Souza (2011) observam que o conhecimento tácito seja subjetivo (necessariamente ligado ao seu detentor), associado à sua experiência (à mente e ao corpo), simultâneo (aqui e agora) e análogo (prática) ao indivíduo que o possui. 
Pesquisa conduzida por Goffin e Koners (2011) junto a empresas alemãs líderes de mercado identificou que a gestão do conhecimento tácito, se bem conduzida pela organização, pode contribuir para a obtenção de ganhos no processo de desenvolvimento de novos produtos pela empresa.

\section{MÉTODO E MATERIAIS}

Esta é uma pesquisa descritiva qualitativa baseada na estratégia de múltiplos estudos de caso, realizada a partir da aplicação de entrevistas com roteiro semiestruturado. A pesquisa foi realizada em duas empresas do setor automobilístico localizadas na Região do $A B C$ (SP), nas quais seis funcionários se dispuseram a participar do estudo.

Os critérios para a escolha das unidades de análise se deram por meio da seleção de um único segmento (automobilístico). No caso do presente estudo, o ramo automobilístico foi escolhido dado a sua importância econômica para os municípios da Região do ABC paulista. As empresas selecionadas têm equivalência quanto ao porte e ao número de funcionários, efetivando atividades relevantes na área de desenvolvimento de produtos.

A identidade das empresas (Alfa e Beta) e dos participantes foi preservada por questões de sigilo solicitado pelos respondentes. Assim, visando preservar as identidades dos envolvidos, foram utilizadas siglas para a caracterização destes na exposição dos resultados. Dentre os critérios de seleção dos respondentes, estão o tempo de trabalho e experiência na organização, cargo atual e experiência na área de projetos de desenvolvimento de produtos. Esta pesquisa contou com o relato de seis entrevistados, cujos perfis são descritos a seguir:

a) Empresa Beta: Entrevistado 1 (E1) - Bacharel em sistemas de informação com 9 anos de empresa e 3 anos no cargo; Entrevistado 2 (E2) - Engenheiro mecânico com 9 anos de empresa e 5 anos no cargo.

b) Empresa Alfa: Entrevistado 3 (E3) - Engenheiro mecânico de anos com 22 anos de empresa e 15 anos no cargo; Entrevistado 4 (E4) - Engenheiro mecânico com 16 anos de empresa e 7 anos no cargo; Entrevistado 5 (E5) - Tecnólogo em Mecânica e bacharel em Matemática com 40 anos de empresa e 25 anos no cargo; Entrevistado 6 (E6) - Técnico em Mecânica de Manutenção com 38 anos de empresa e 25 anos no cargo. Todos trabalham na área de engenharia e desenvolvimento de projetos.

Assim, foram realizadas seis entrevistas com gestores de funcionários da área de projetos de desenvolvimento de produtos das duas organizações. 0 roteiro de entrevistas foi composto por três blocos com questões relacionadas às seguintes categorias de análise: a) Perfil da empresa e do respondente, b) Identificação das principais práticas utilizadas para a captura e disseminação do conhecimento tácito e c) Identificação das principais contribuições das práticas voltadas à captura e disseminação do conhecimento tácito.

\section{APRESENTAÇÃO E ANÁLISE DOS RESULTADOS}

Neste capítulo são apresentadose analisados os principais resultados auferidos na pesquisa de campo efetuada nos dois casos considerados, doravante denominados empresa Alpha e empresa Beta. Ao final, é apresentada ainda a análise cruzada dos resultados de ambos os casos estudados, confrontando-os com a literatura a respeito da temática abordada.

\subsection{Estudo de caso: empresa Alfa}

A seguir são apresentados os resultados verificados no estudo de caso da empresa Alpha. Primeiramente são expostas as práticas utilizadas na empresa para a conversão do conhecimento tático em conhecimento organizacional. Na sequência são elencadas as principais contribuições da aplicação dessas práticas para a empresa. Por fim, são estabelecidas considerações gerais a respeito dos principais resultados verificados na empresa Alpha. 


\title{
4.1.1 Práticas usadas para a conversão do conhecimento tácito na empresa Alfa
}

Há de se considerar que no ambiente organizacional muitas das práticas utilizadas no cotidiano das equipes não estão registradas em manuais ou em banco de dados, pois estão conectadas às ações internas daquela equipe. Ações que são muitas vezes executadas de maneira inconsciente, pois fazem parte do próprio ritmo de trabalho dos indivíduos envolvidos.

0 atual contexto econômico foi abordado durante a entrevista, pois as empresas ligadas ao ramo automobilístico passam por dificuldades ligadas a questões econômicas; o que pode ser identificado na fala do E4, que indica:

\begin{abstract}
A gente [a empresa] está numa condição não muito favorável. Assim, não é discutida abertamente, mas também não se incentiva né. A gente está realmente esperando para que o mercado melhore para a gente voltar. Mas normalmente, essencialmente elas são um incentivo para que seus colaboradores façam treinamentos (E4).
\end{abstract}

Ainda sobre a questão das práticas usadas para a conversão do conhecimento tácito, o Entrevistado 5 (E5) indica que há incentivos por parte da organização, sinalizando ainda a respeito da importância da relação com o departamento de recursos humanos:

\begin{abstract}
Nós criamos um curso interno para disseminar mais conhecimento entre as áreas não só de Engenharia mas outras áreas da fábrica que quando a gente tem um desnível de informações vamos dizer o conhecimento, quando ele não é uniforme, ele gera muito estresse. Então nós decidimos junto com o RH de fazer um trabalho em conjunto oferecendo para áreas de Qualidade, de Compras, outras áreas também correlatas, um curso de formação na área de automobilística (E5).
\end{abstract}

Sobre o incentivo por parte da organização para a constante especialização, E6 indica que os departamentos têm uma previsão anual para o ano seguinte. A respeito do mesmo questionamento, E3 corrobora com as informações de E5 e indica que há o apoio do setor de Recursos Humanos em relação às necessidades de treinamento ou especialização das funções exercidas pelos funcionários: "Você também pode fazer um planejamento de treinamento naquilo que sua atividade específica requer" (E3).

Todos os entrevistados da empresa Alfa indicaram que o incentivo à especialização é fator presente, porém há de se analisar as questões financeiras da organização devido às limitações impostas pelo mercado na atualidade. Tais ações indicam que o profissional deve estar em constante especialização e construção do seu conhecimento.

\subsubsection{Principais contribuições das práticas voltadas à disseminação do conhecimento tácito na empresa Alfa}

Segundo as contribuições do entrevistado $\mathrm{E} 3$, as práticas não eficazes para a disseminação do conhecimento tácito têm relação com os cursos obrigatórios, àqueles impostos pela empresa. Por outro lado, em sua opinião, as práticas que funcionam são as que envolvem trabalhos multidisciplinares.

De acordo com a contribuição do entrevistado E4, as melhores práticas são aquelas nas quais o gestor da área consegue a identificação de pares na equipe. Ou seja, tornou-se um exercício diário a identificação destes profissionais e a relação entre as duplas de trabalho. Porém, um elemento dificultador desta ação reside na própria rotina de trabalho e na falta de tempo para o estímulo ao desenvolvimento destas relações de parceria.

O entrevistado E5 indica que a burocratização de muitos processos tornou-se um impedimento, uma vez que é necessário "escrever muito". Além disso, não há interesse dos funcionários em buscar informações anteriores através de manuais: "é difícil você catalogar uma coisa dessas".

Sob uma ótica diferenciada dos entrevistados da empresa Alfa, E6 indica que os métodos mais eficazes são as reuniões dos grupos e brainstorming: 
Acho que são as reuniões e reuniões de projetos (brainstorming). 0 segundo não é praticado tal como deveria, acho que ele poderia ser melhor explorado por parte das equipes. Eu acredito que são nestes momentos que se acaba tendo as melhores ideias e soluções para os problemas que podem ocorrer na nossa rotina de trabalhor (E6).

\subsubsection{Considerações sobre o caso da empresa Alfa}

Verificou-se nas falas dos entrevistados que as ações de socialização do conhecimento estão presentes nas relações de trabalho das equipes em que os participantes atuam. Por meio de seus relatos é perceptível que o processo de compartilhamento de informações, que se processa por meio do conhecimento tácito, modelos mentais ou habilidades compartilhadas pela equipe de trabalho, faz parte de suas rotinas de trabalho.

Os processos de comunicação e de parceria nas funções cotidianas estão presentes na empresa Alfa e, conforme indicado pelos entrevistados, além de ponto importante para o desenvolvimento das atividades, a parceria se faz necessária nas relações de trabalho e/ou trabalho de equipes multifuncionais/multidisciplinares para o desenvolvimento de um projeto.

Identificou-se ainda que a comunicação é fator essencial para a resolução de problemas, além de ser facilitadora na interação da equipe quando das trocas de conhecimentos tácitos, mesmo em momentos em que a informalidade se apresenta nas rotinas de trabalho. Outro ponto abordado nas entrevistas é a questão do acúmulo de funções e a disponibilidade de tempo, situações nas quais os indivíduos podem ter momentos exclusivos para a troca de experiências entre si.

Em relação aos aspectos tácitos identificou-se que os funcionários entrevistados abordam a importância da troca de experiências entre funcionários mais velhos e mais novos na organização. Demonstrou-se por meio dos relatos que há procedimentos formais por parte da organização para o registro do conhecimento. Além desta preocupação organizacional, de acordo com os entrevistados, verificou-se que em adição aos processos formais, uma grande parte do processo de disseminação do conhecimento tácito é focada no indivíduo.

Existe uma preocupação, por parte dos gestores entrevistados, quanto aos funcionários que estão aposentados e, que continuam na organização ou com aqueles que estão em vias de aposentar-se, pois são pessoas-chave nas equipes em que atuam, e sua permanência dependerá de políticas internas e questões econômicas da organização estudada.

Dentre as práticas mais utilizadas e que, na percepção dos entrevistados, são consideradas de grande valia para 0 desenvolvimento de suas atividades, está a questão das equipes multifuncionais/multidisciplinares. De acordo com os relatos, esta troca de conhecimentos é fator considerado importante para a execução das tarefas e resolução dos problemas.

Outro processo evidenciado são as reuniões que se tornam parte integrante das rotinas de trabalho, seja por meio de reuniões agendadas e formalizadas, os knowledge cafés ou brainstorming (por meio do agendamento prévio) ou àquelas reuniões ditas informais que se referem ao encontro de funcionários em momentos ocasionais.

\subsection{Estudo de caso: empresa Beta}

Nesta seção são apresentados os resultados auferidos no estudo de caso da empresa Beta. De início são expostas as práticas utilizadas na empresa para a conversão do conhecimento tático em conhecimento organizacional. A seguir são indicadas as principais contribuições desta aplicação para a empresa. Como fechamento deste caso são estabelecidas considerações gerais a respeito dos principais resultados alcançados pela empresa Beta. 


\subsubsection{Práticas usadas para a conversão do conhecimento tácito na empresa Beta}

Os entrevistados E1 e E2 indicam que as ações relativas à disseminação de conhecimento tácito fazem parte de suas rotinas de trabalho. E1 indica que "é uma ação constante, [...] este ano eu tenho como meta estudar espanhol [...] e depois de seis meses, [...] é feito uma reavaliação pra ver se você deu andamento".

$\mathrm{O}$ entrevistado E2 corrobora com a fala de E1, porém indica que esta ação sofre muito devido às crises no mercado automobilístico. Complementando as informações apresentadas sobre a questão das especializações, E2 indica que ocorre o incentivo por parte da organização para a constante especialização: "sim eu tive uma pós-graduação paga, duas pós-graduações [...]. Além de cursos regulares. Ela é constante, mas ela sofre muito com as crises".

O incentivo da constante especialização faz parte das rotinas apresentadas nas respostas dos entrevistados E1 e E2 indicando que o único fator restritivo atualmente seriam as dificuldades econômicas.

\subsubsection{Principais contribuições das práticas voltadas à disseminação do conhecimento tácito na empresa Beta}

O entrevistado E1 indica que na realidade existe um grupo de estudo, o qual passa por transformações constantes por trabalhar diretamente com tecnologia. Desta forma, há uma equipe piloto responsável por elaborar um manual descritivo de todos os procedimentos relativos ao projeto do momento. Em complemento, o respondente E2 não compartilha da mesma percepção, pois acredita que não ocorre esta transformação de conhecimento informal para formal, uma vez que se trata de uma grande empresa multinacional.

O entrevistado E1 indica existir o hábito dos funcionários discutirem problemas de trabalho do cotidiano em seus momentos livres, principalmente dos funcionários que trabalham no mesmo andar em função do próprio layout do ambiente de trabalho:

\footnotetext{
Então na verdade a gente acaba compartilhando informação quando você está no mesmo andar, então não é separado por baia, não tem parede é uma coisa bem extensa, então você acaba conhecendo todo o grupo que trabalha. Evidentemente que você tem um pouco mais de familiaridade com alguns, afinidade mais com alguns. Então você acaba trocando experiências nas dificuldades que você está tendo em determinadas situações (E1).
}

Diferentemente da resposta de E1, o entrevistado E2 indica que nestes momentos o foco principal é na crítica e não em informações que levem à solução de uma dificuldade. Ainda sobre as principais contribuições das práticas a respeito da busca de informações com pessoas externas à organização, E1 indica que todos os processos são internos, considerando que o suporte da empresa brasileira é a própria matriz, no caso, por exemplo, em que ocorra a necessidade da busca de algum auxílio externo. Somente a matriz tem esta autonomia. $O$ entrevistado E2 indica que quando é necessário busca-se o auxílio de pessoas: "eu sempre uso os mais experientes e valorizo os que fazem o mesmo".

Dentre as práticas da equipe de trabalho do entrevistado E1 ressalta-se que sua rotina depende prioritariamente do escopo do trabalho executado naquele momento, ou seja, as práticas dependerão da necessidade do momento, conforme indicado por E1:

Quando têm situações pouco mais controladas, a gente faz aquele bate-papo de café mesmo pra trocar experiência e existe, nós temos lá uma área chamado application manager que é uma área um pouquinho separada, um departamento só que cuida de atendimento de problemas [tá]. Então essa área uma vez por mês ela faz um reporte pro time explicando quais são as ocorrências, as dificuldades o que está acontecendo durante o mês (E1)

De acordo com E2, as práticas mais frequentes em suas rotinas de trabalho são narrativas, brainstorming (com muita frequência), socialização (em menor quantidade), sendo que reuniões e cafés são muito utilizados também. 


\subsubsection{Considerações sobre o caso da empresa Beta}

De acordo com os relatos dos entrevistados E1 e E2, a empresa possui diferenças em suas rotinas de trabalho, sendo que ambos os participantes trabalharam na área de projetos. Contudo, verifica-se certas diferenças em seus ambientes de trabalho, uma vez que há aspectos divergentes nas duas entrevistas em razão das rotinas de trabalho das equipes.

Em ambas as entrevistas demonstrou-se a preocupação por parte da empresa em estimular cursos de especialização, de acordo com as áreas de atuação dos funcionários, porém a conjuntura econômica interfere na concessão de subsídios dessa natureza.

A troca de conhecimento tácito é uma questão sempre evidenciada nas práticas cotidianas na empresa Beta. Segundo relatos dos entrevistados, a empresa reforça esta necessidade, além de incentivá-la constantemente. Quanto à troca de conhecimento entre gestores e funcionários, o entrevistado E1 indica que dependerá do projeto que está sendo executado naquele momento. Já o entrevistado E2 corrobora tal afirmação, porém quanto à troca de conhecimento em relação aos pares há divergências entre os dois entrevistados, pois de acordo o El existe o acompanhamento do recém-chegado à organização até 0 momento em que este compreenda os processos internos. Contudo, de acordo com E2, o novo funcionário não possui este acompanhamento inicial.

Como resultado da análise das práticas e iniciativas de disseminação de conhecimento tácito na empresa Beta, percebeu-se uma preferência por métodos formais, ou seja, métodos instituídos pela própria organização. Isto deve-se ao tempo corrido e à elevada demanda de trabalho, que não favorecem a transmissão de conhecimento de maneira informal ou mais pessoal, inerentes ao conhecimento tácito dos indivíduos. Trata-se de uma empresa multinacional que segue procedimentos padronizados e, além dos seus padrões preestabelecidos, se faz necessário verificar a disponibilidade dos indivíduos em partilhar os conhecimentos com o restante da equipe.

\subsection{Análise cruzada dos resultados dos casos das empresas Alfa e Beta}

As principais práticas verificadas nas duas empresas para a disseminação do conhecimento tácito foram bastante similares, possivelmente em razão de ambas atuarem no setor automobilístico. A empresa Alpha dispõe de cursos de especialização, cursos regulares, conversas informais, knowledge cafés, so cialização de indivíduos, sessões de brainstorming e lições aprendidas. Já a empresa Beta desenvolve o PDI (plano de desenvolvimento individual), cursos de especialização, cursos regulares, conversas informais, knowledge cafés, socialização de indivíduos e sessões de brainstorming.

Diante das informações levantadas verifica-se grande convergência entre as empresas Alfa e Beta quanto às práticas utilizadas para a disseminação do conhecimento tácito. Corroborando as informações apresentadas nas práticas evidenciadas nas empresas Alfa e Beta, Dalkir (2005) indica haver uma série de outras técnicas que podem ser utilizadas para capturar e disseminar o conhecimento tácito dos indivíduos e grupos, que incluem "sessões $a d$ hoc", mapas, histórias de aprendizagem, aprendizagem em ação, e-learning, além do aprendizado com outros, por meio de palestrantes convidados e benchmarking com as melhores práticas.

Sobre as principais contribuições das práticas e iniciativas voltadas para a disseminação do conhecimento tácito, na perspectiva de gestores entrevistados, há a constante preocupação em se disseminar o conhecimento tácito para os demais membros da equipe, isto em função de questões relativas à situação econômica, na qual alguns membros antigos da equipe podem ser desligados de suas funções a qualquer momento, pois já estão aposentados e continuam trabalhando ativamente.

Desta forma, o conhecimento tácito destes membros poderá não ser repassado aos outros funcionários e, por consequência, algumas de suas habilidades e conhecimentos específicos podem não ser disseminadas na empresa. Não obstante, em ambas as empresas verificou-se a preocupação de promover reuniões e conversas constantes, mesmo em âmbito informal, proporcionando assim o diálogo entre os membros das equipes, visando assim a troca de conhecimentos. 
A partir das informações levantadas nas entrevistas, identificou-se nas empresas Alfa e Beta ações similares relacionadas à disseminação do conhecimento tácito, indicando que as práticas empregadas são executadas muitas vezes de maneira natural (informal). Ou seja, sem a preocupação formal de se registrar tais procedimentos por parte dos funcionários para que assim o conhecimento tácito se transforme em conhecimento formal registrado na organização, de forma a tornar perenes os conhecimentos dos indivíduos em prol do conhecimento organizacional formalizado.

\section{CONCLUSÃo}

Os resultados auferidos na pesquisa de campo efetuada indicaram vários pontos de convergência entre as práticas desenvolvidas pela empresa Alfa e pela empresa Beta, principalmente aqueles relativos à forma empregada pelas organizações estudadas para estimular a constante atualização de seus funcionários. Porém, é importante ressaltar a preocupação das empresas analisadas relativamente às questões macroeconômicas que afetam o mercado automobilístico no momento da pesquisa de campo, que acabaram por impactar no contexto apresentado em função da retenção de custos relativos à oferta de cursos de atualização aos colaboradores.

Pôde-se verificar a existência de preocupação com as ações voltadas à gestão do conhecimento nas empresas estudadas. Nesse sentido, ambas as empresas desenvolveram práticas diversas relativas à estimulação da criação e disseminação do conhecimento tácito, embora a operacionalização destas tenha assumido características distintas em cada uma delas. As práticas de criação e disseminação de conhecimento tácito verificadas foram o incentivo a cursos regulares e de especialização, socialização de indivíduos por meio de reuniões periódicas e conversas informais constantes, grupos de estudo, brainstorming, lições aprendidas, knowledge cafés e conversas informais entre os colaboradores.

A análise das entrevistas demonstrou que o processo de disseminação de conhecimento tácito e sua transformação em conhecimento explícito dependem de fatores ligados à própria organização, bem como de fatores ligados aos próprios indivíduos envolvidos. Ou seja, depende do indivíduo, no que se refere à aceitação em transmitir o que sabe, bem como dos demais envolvidos no processo em receber a informação e transformá-la em conhecimento a ser aplicado em suas rotinas. Assim, observou-se que o conhecimento tácito do indivíduo tem como base a sua vivência prática, além do acúmulo de informações que obteve ao longo de sua vida.

No estudo não foi identificado apenas um único método eficaz de disseminação ou transformação do conhecimento, pois de acordo com as entrevistas é a combinação de vários métodos que auxilia na resolução dos problemas que possam surgir no decorrer da execução das tarefas, além da própria dinâmica daquela equipe, mediante a postura adotada em seu cotidiano.

A gestão do conhecimento tácito e sua consequente transformação em conhecimento explícito ainda encontram dificuldades nas organizações. Contudo, por meio do estudo do tema pôde-se verificar que há crescente preocupação por parte das organizações em registrar o maior número de informações de seus funcionários nas funções em que ocupam antes do desligamento dos mesmos, como forma de registrar e armazenar determinados conhecimentos que aquele indivíduo possui. Entretanto, tais iniciativas acabam por ser uma tarefa árdua e constante, pois com a atual dinamicidade das informações e conhecimentos, as mudanças ocorrem rapidamente.

A partir das questões levantadas neste estudo constata-se que o conhecimento tácito é percebido, por parte dos funcionários, como forma de troca de experiências. Porém, o fator 'disponibilidade' foi considerado um impedimento para a troca de conhecimentos entre os membros das equipes, além da própria relação entre os pares. A preocupação por parte dos gestores também é evidenciada nas entrevistas e, existe a preocupação de manter o máximo de informações para todos os membros da equipe, principalmente em relação aos membros que podem não fazer mais parte da equipe, por diversas razões, além do fato de serem responsáveis por estimular tais relações entre os integrantes de seus times.

A presente pesquisa apresenta algumas limitações a serem consideradas, como a restrição a dois casos analisados, tendo como contingente de sujeitos respondentes seis colaboradores das duas organizações 
pesquisadas. Também há de se ressaltar o recorte geográfico aplicado às empresas analisadas, uma vez que ambas se localizam na Região do ABC (SP). Não obstante, também houve restrição quanto aos processos enfocados nesta pesquisa, uma vez que a ênfase dada voltou-se ao processo de desenvolvimento de produtos. Algumas sugestões para pesquisas futuras extensivas ou complementares são indicadas: realização de pesquisas em outras regiões ou setores econômicos, bem como em outros processos internos das empresas prospectadas. Outras pesquisas poderiam se aprofundar mais nas características das práticas de disseminação de conhecimentos tácitos encontradas neste estudo.

\section{REFERÊNCIAS}

ALMEIDA, M. S.; FREITAS, C. R.; SOUZA, M. S. Gestão do conhecimento para tomada de decisão. São Paulo: Atlas, 2011.

AMORIN, B.; TOMAÉL, M. I. Gestão da informação e gestão do conhecimento na prática organizacional: análise de estudos de casos. Revista Digital de Biblioteconomia e Ciência da Informação, Campinas, v. 8, n. 2, p. 1-22, jan./jun. 2011.

ANDRADE, M. T. T.; FERREIRA, C. V.; PEREIRA, H. B. B. Uma ontologia para a gestão do conhecimento no processo de desenvolvimento de produto. Gest. Prod., São Carlos, v. 17, n. 3, p. 537-51, 2010.

BRITO, L. M. P.; GALVÃO, A. G.; OLIVEIRA, P. W. S. Gestão do conhecimento em empresa internacional de energia. In: ENCONTRO DA ANPAD, 36., 2012, Rio de Janeiro. Anais [...]. Rio de Janeiro: ANPAD, 2012. p. 1-14.

CARBONE, P. P. et al. Gestão por competências e gestão do conhecimento. 3. ed. Rio de Janeiro: FGV, 2009.

CARVALHO, H. G.; HINÇA, A. Escritório de projetos como ferramenta de gestão do conhecimento. 2004. Disponível em:www.pg.utfpr.edu.br/ppgep/Ebook/ Artigos/19.pdf. Acesso em: 30 maio 2014.

CENTENARO, A.; BONEM BERGER, A. M. O.; LAIMER, C. G. Gestão do conhecimento e vantagem competitiva. Revista de Ciências da Administração, v. 18, n. 44, p. 38-51, abr. 2016.

DALKIR, K. Knowledge management in theory and practice. Burlington: Elsevier, 2005.

DAVENPORT, T. H.; PRUSAK, L. Conhecimento empresarial: como as empresas gerenciam o seu capital intelectual. Rio de Janeiro: Campus, 1998.

EISENHARDT, K. M.; SANTOS, F. M. Knowledge-based view: A new theory of strategy? In: PETTIGREW, A.; THOMAS, H.; WHITTINGTON, R. (ed.). Handbook of strategy and management. London: Sage, 2002. p. 13964.

FERRARESI, A. A. et al. Knowledge management and strategic orientation: leveraging innovativeness and performance. Journal of Knowledge Management, v. 16, n. 5, p. 688-701, 2012.

FILENGA, D. Detalhando o reconhecimento de valor na capacidade absortiva: uma proposta de operacionalização. In: ENCONTRO DA ANPAD, 38., 2014, Rio de Janeiro. Anais [...]. Rio de J aneiro: ANPAD, 2014. p. 1-15.

FLEURY, M. T. L. As pessoas na organização. São Paulo: Gente, 2002.

GOFFIN, K.; KONERS, U. Tacit knowledge, lessons learnt, and new product development. Journal of Product Innovation Management, Medford, v. 28, n. 2, p. 300-18, Feb. 2011.

KLEIN, D. A. A gestão estratégica do capital intelectual: recursos para a economia baseada em conhecimento. Rio de Janeiro: Qualitymark 1998. 
KUNIYOSHI, M. S. et al. Institucionalização do knowledge based view: um estudo das Práticas gerenciais de gestão do conhecimento e suas Contribuições para a competitividade das empresas do setor elétricoeletrônico. Revista de Administração da UNIMEP, Piracicaba, v. 11, n. 2, p. 1-30, maio/ago. 2013.

LEITE, D. M.; GONTIJ O, S. L. S. C; MENEGHELLI, A. Criando conhecimento nas organizações. In: RODRIGUEZ Y RODRIGUES, M. V. (org.). Gestão do conhecimento nas empresas. Rio de J aneiro: Qualitymark, 2010. p. 94121.

LÓPEZ-NICOLÁS, C.; MEROÑO-CERDÁN, A. L. Strategic knowledge management, innovation and performance. International J ournal of Information Management, Amsterdam, v. 31, n. 6, p. 502-09, Dec. 2011.

NONAKA, I.; TAKEUCHI, H. Criação de conhecimento na empresa: como as empresas japonesas geram a dinâmica da inovação. Rio de J aneiro: Campus, 1997.

NONAKA, I.; VON KROGH, G. Perspective-tacit knowledge and knowledge conversion: Controversy and advancement in organizational knowledge creation theory. Organization Science, v. 20, n. 3, p. 635-652, May 2009.

PORTER, M. Vantagens competitivas: criando e sustentando um desempenho superior. Rio de Janeiro: Campus, 1998.

SANTOS, A. E. M.; POPADIUK, S. A gestão do conhecimento e a Capacidade de competição. Contextus: Revista Contemporânea de Economia e Gestão, v. 8, n. 1, p. 21-32, jan./jun. 2010.

SILVA, A. F. et al. Análise de redes sociais informais: ferramenta para o compartilhamento do conhecimento organizacional. In: ENCONTRO DA ANPAD, 35., 2011, Rio de Janeiro. Anais [...]. Rio de Janeiro: ANPAD, 2011. p. 1-16.

TEIXEIRA FILHO, J. Gerenciando conhecimento. Rio de Janeiro: SENAC, 2000.

WONG, K. Y. Knowledge management performance measurement: measures, approaches, trends and future directions. Information Development, v. 29, p. 3-19, 2013. 